\title{
Building a Companion Website in the Semantic Web
}

\author{
Timothy Miles-Board \\ tmb@ecs.soton.ac.uk \\ Wendy Hall \\ wh@ecs.soton.ac.uk
}

\author{
Christopher Bailey \\ cpb@ecs.soton.ac.uk \\ Leslie Carr \\ lac@ecs.soton.ac.uk
}

Intelligence, Agents, Multimedia Group

University of Southampton

Southampton, UK

\begin{abstract}
A problem facing many textbook authors (including one of the authors of this paper) is the inevitable delay between new advances in the subject area and their incorporation in a new (paper) edition of the textbook. This means that some textbooks are quickly considered out of date, particularly in active technological areas such as the Web, even though the ideas presented in the textbook are still valid and important to the community. This paper describes our approach to building a companion website for the textbook Hypermedia and the Web: An Engineering Approach. We use Bloom's taxonomy of educational objectives to critically evaluate a number of authoring and presentation techniques used in existing companion websites, and adapt these techniques to create our own companion website using Semantic Web technologies in order to overcome the identified weaknesses. Finally, we discuss a potential model of future companion websites, in the context of an e-publishing, e-commerce Semantic Web services scenario.
\end{abstract}

\section{Categories and Subject Descriptors}

H.3.5 [Information Storage and Retrieval]: Online Information Services-Web-based services; H.5.4 [Information Interfaces and Presentation]: Hypertext/Hypermedia; I.7.4 [Document and Text Processing]: Electronic Publishing; J.7 [Computer Applications]: Computers in Other Systems-Publishing

\section{General Terms}

Human Factors

\section{Keywords}

Textbook, Companion Website, Electronic Publishing, Bloom's Taxonomy, Semantic Web

\section{INTRODUCTION}

The textbook Hypermedia and the Web: An Engineering Approach [15] (co-authored by Wendy Hall, one of the authors of this paper) describes in detail a principled approach to the design, production, and maintenance of large hypermedia applications; a resource which we feel ongoing activity in Web application design $[5,24,25]$ demonstrates is still valid (and potentially valuable) in the context of the Web engineering community. However, in

Copyright is held by the author/owner(s).

$W W W 2004$, May 17-20, 2004, New York, New York, USA.

ACM 1-58113-844-X/04/0005.

\begin{tabular}{ll}
\hline Competence & Skills Demonstrated \\
\hline Knowledge & Recalls previously learned material. \\
Comprehension & Grasps the meaning of learned material. \\
Application & Uses learned material in new situations. \\
Analysis & $\begin{array}{l}\text { Breaks down material into its compo- } \\
\text { nent parts in order to understand its or- }\end{array}$ \\
& $\begin{array}{l}\text { ganisational structure. } \\
\text { Pynthesis }\end{array}$ \\
$\begin{array}{l}\text { Put parts together to form a new whole. } \\
\text { Jualuation the value of material for a given } \\
\text { purpose. }\end{array}$ \\
\hline
\end{tabular}

Table 1: Bloom's Taxonomy of educational objectives.

the rapidly evolving field of Web research, much of the textbook's background and research-related content (approx. 50\% of the material), although perhaps useful for newcomers to the field, is now out of date. To address this problem, we decided to try and bring the textbook up to date by building a "companion website"1 which would extend the coverage of the textbook and demonstrate how more recent work in the community still fits in with the framework for hypermedia engineering it proposes.

\section{TEXTBOOKS AND BLOOM'S TAXON- OMY}

A primary goal of the Hypermedia and the Web textbook, as with many textbooks, is to educate, and material aimed at a wide range of readership profiles, including researchers, practitioners, designers, managers, information experts and students, is covered. In 1956, educational psychologist Benjamin Bloom chaired a committee charged with developing a classification system that captured the intellectual behaviour important in learning [3]. The resulting hierarchy of intellectual skills involving the acquisition and use of knowledge in the cognitive domain ${ }^{2}$, generally referred to as Bloom's Taxonomy, categorises cognitive learning objectives ranging from simple recall to the ability to judge and evaluate material (Table 1).

In the context of this paper, Bloom's taxonomy gives us a way of

\footnotetext{
${ }^{1}$ A term used in popular Web parlance to describe a site which is intended to function as a supplement to a non-electronic resource such as a textbook.

${ }^{2}$ Bloom and his colleagues actually identified and delineated three overlapping domains: cognitive, affective, and psychomotor; we focus here on the cognitive domain.
} 
describing and critiquing the features that companion websites offer. We argue that it is valid to transfer the taxonomy from judging students in the educational domain to judging websites in the computer systems domain because the taxonomy describes observable intellectual behaviour as opposed to abstract beliefs. Hence, we can reasonably state that, for example, a website providing a list of departmental contact information (telephone, email etc.) does little more than facilitate a reader's recall, whereas a website listing the most influential researchers in a particular field (with justification) could assist the development of a higher level evaluation skill.

Generally speaking, the process of authoring a textbook such as Hypermedia and the Web incorporates each of the intellectual skills listed in the taxonomy, from gathering and reading background material (recall, comprehension) to "fitting" the textbook together and deciding what should and should not be included (synthesis, evaluation). The "success" of a textbook could therefore be considered as dependent on the ability of the authors to effectively communicate their high level understanding of the subject matter in such a way as to facilitate the reader's higher-level learning objectives. In this respect, we are interested in discovering the authoring and presentation techniques that could be employed to create "successful" companion websites that extend their traditional, non-electronic, counterparts. We therefore carried out a review of a number of existing companion websites in order to identify some of these techniques.

\section{REVIEW OF EXISTING COMPANION WEBSITES}

The aim of the review was to identify the techniques used to extend the textbook and present online material. We then related these techniques to the intellectual skills delineated by Bloom's taxonomy, in order to evaluate the learning support provided by each technique. In total, 25 companion websites from a number of different domains were reviewed; see Appendix $\mathrm{A}^{3}$. To better facilitate comparison of the websites, we have categorised the features of the 25 companion websites into four main areas: text, hypertext, student resources, and instructor resources.

\subsection{Text features}

Although more than half of the reviewed sites reproduce some or all of the textbook content in electronic form, either as HTML pages or PS/PDF files ${ }^{4}$, four of the sites provide an extended or updated online text (DrugsBrain, KimBiology, ResStrateg, WebPublish). InsAnatomy provides extended material in the form of hyperlinked anatomy diagrams entirely separate from the original textbook content (an anatomical dictionary).

\subsection{Hypertext features}

Almost all of the sites use the hierarchical structure of the textbook as a (hypertextual) presentation device, with each page of the website mapped to a chapter, section, or article/lecture in the case of those textbooks representing a collection of works by different authors. Exceptions are InsAnatomy and KimBiology. InsAnatomy's nodes are anatomy diagrams; John Kimball, the author of KimBiology, reveals his approach in the introduction to his com-

\footnotetext{
${ }^{3}$ These sites were selected randomly using Google searches and resources such as the list of Online Science and Maths Textbooks http://spot.colorado.edu/ dubin/bookmarks/b/ $1240 . h t m l$

${ }^{4}$ Although note that some companion websites may not be published by, or under the control of, the textbook authors, e.g. FamPractic, ElemsStyle, StatsSqOne
}

panion website, which led him to break down the linear textbook content into a number of concise "topics" (one per Web page):

It has always seemed to me that the many parts that make up the subject of biology are related to each other more like the nodes of a web than as a linear collection of independent topics. So I believe that the power of hypertext will be better suited to learning about biology than is the linear structure of a printed textbook.

Over half of the companion websites use a linked table of contents to allow readers quick access to the material. In the majority of cases, the table of contents is reproduced directly from the textbook, and linked to each node of the site (e.g. AmericGeog); in the cases where the textbook content is not reproduced, the table of contents serves as a means of accessing other resources related to each part of the textbook (e.g. Geosystems, PowerTools). Again InsAnatomy and KimBiology are the exceptions: InsAnatomy uses a graphical table of contents based on the human body (e.g. head $\rightarrow$ organs $\rightarrow$ ear $\rightarrow$ drum); KimBiology lists topic pages by category (e.g. Animals, Behaviour, Biochemistry). Several sites also provide a site-specific search engine as a further means of finding relevant material (e.g. BrainWorks, MedMicrobi).

In terms of hypertext linking features, four types of linking practice were identified: tour links (move to next/previous node in a linear sequence — cf. Navigation links [11]), glossary links (subjectspecific terms in the material linked to definitions - cf. Expansion links [11]), cross-reference links (related ideas in the material tied together with associative [6, 18] links — cf. Resource links [11]), and external links (links to related material on other websites cf. Resource links [11]). All sites which demonstrated tour linking mirrored the linear sequence of the textbook: readers can follow links to the next/previous chapter or section. KimBiology, the only site which demonstrates a cross-reference linking strategy, not only makes concrete non-linear relationships between the many different topics, but also (in the majority of topics) explicitly suggests that readers should carefully compare the current topic with several other (linked) topics. Some companion websites provide a single list of external links to accompany the entire textbook (e.g. EricMeyCss), some present external links in the context of nodes (e.g. WebPublish); in either case, the external links may be annotated (e.g. with indications of the target audience of the linked material BrainWorks).

\subsection{Student Resources}

Less than half of the companion websites provide resources for students, peripheral to the textual content, in the form of exercises, projects, or quizzes. Other resources provided include an online answer checker (LightMattr), facilities for students to email their answers to instructors (PowerTools, Geosystems), and study guides/workbooks (ResStrateg, WebPublish).

\subsection{Instructor Resources}

In half of the above cases, the student resources were accompanied by syllabi to assist instructors teaching courses related to or based around the textbook. Other instructor resources include a syllabus manager (Geosystems), instructor manuals (PowerTools, LightMattr), and example lecture slides (MolBiology).

It is interesting to note that the Geosystems companion website is just one of a number of sites with similar style and content accompanying textbooks by the Prentice-Hall group of publishers, indicating that a "framework" for building companion websites is available for authors to "fill" with supplementary material, the pop- 


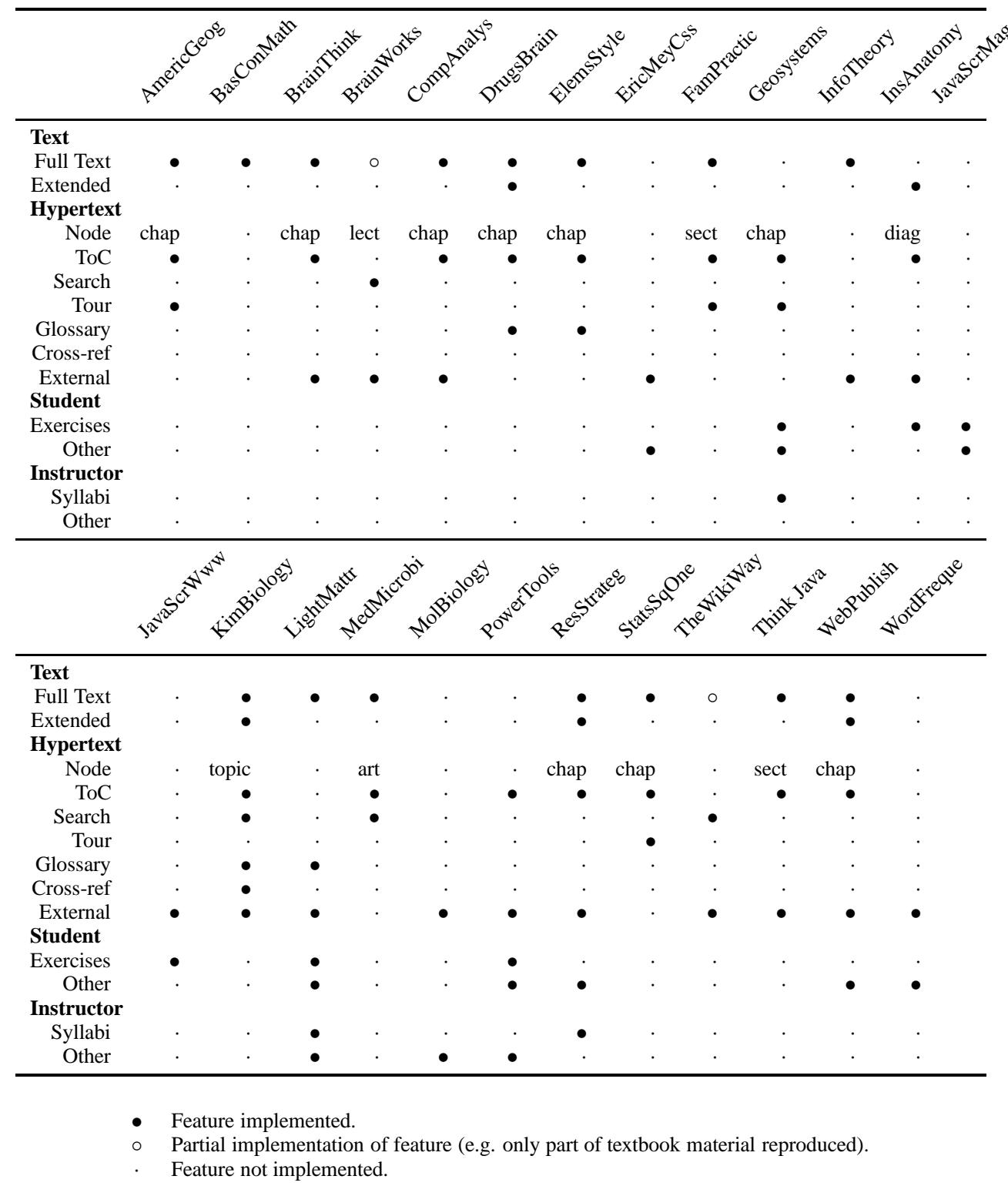

Table 2: Summary of reviewed companion websites

ulated site then being hosted by the publisher ${ }^{5}$. Students register their profile (including email addresses of up to 3 instructors), and can subsequently submit answers to chosen instructors from any Prentice-Hall companion website. The introduction to the Geosystems site hints at some of the possibilities of this "framework" approach for authors with little Web authoring experience to produce resources which help readers both review the content of the textbook and expand upon it:

The Geosystems Companion Website was designed around the chapter structure found in the new fourth edition of this popular text...To start your journey through this site, select a chapter using the drop-down list below, then click "Begin." You'll find that each chapter contains a variety of different types of review questions

\footnotetext{
${ }^{5}$ See Prentice-Hall's Companion Website Gallery - http:// www.prenhall.com/pubguide/index.html
}

- true or false and fill in the blank questions will test your knowledge of the subject matter, while labelling, essay, and critical thinking modules will help you put together what you've learned [...] Each chapter also contains carefully selected and annotated Web destinations for further exploration of the topic at hand, along with a Net Search feature that helps you formulate your own customized Web searches.

Table 2 summarises the features of each companion website.

\subsection{Companion Websites and Bloom's Taxon- omy}

Those companion websites which reproduce the textbook content, and/or provide devices such as a linked table of contents into the material, glossary links, or a search engine could be considered to assist the reader's recall and comprehension by offering fast access to the material (although consider a linked table of con- 


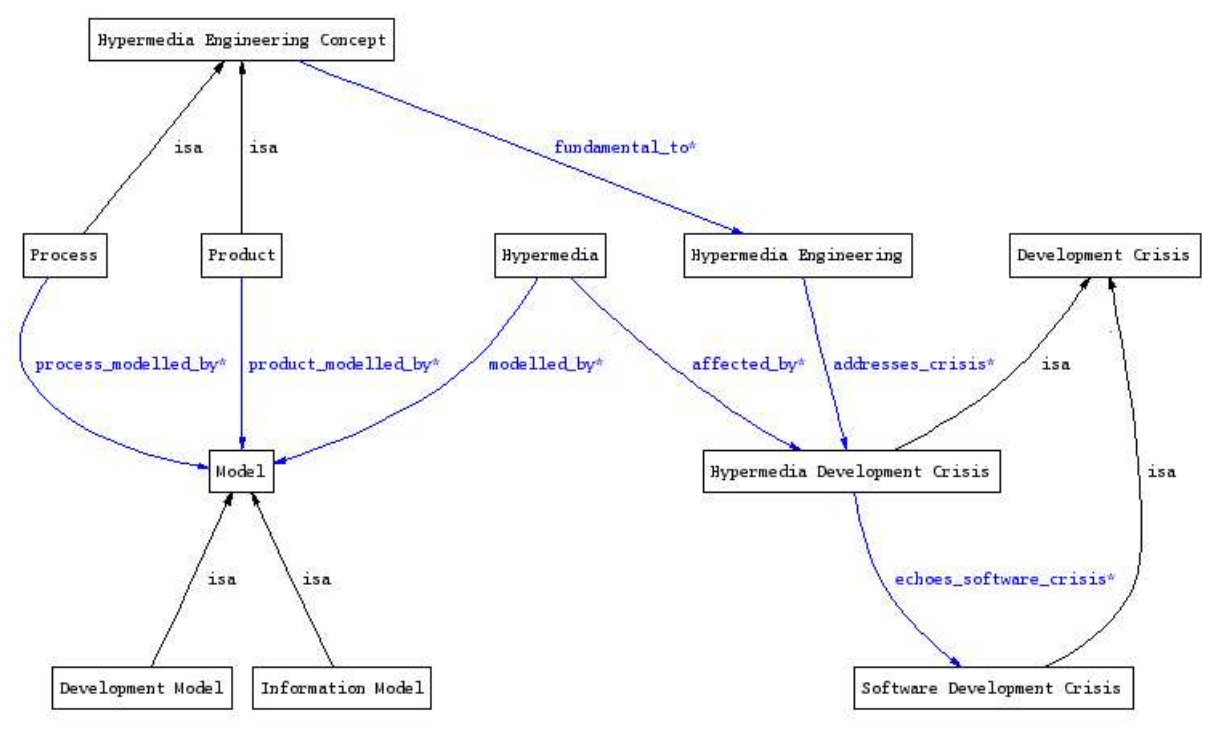

Figure 1: Fragment of the "Hypermedia Engineering” ontology.

tents/search engine in comparison to a textbook index as a recall device). However, the review also identified at least four authoring and presentation techniques which could facilitate the reader's progression to the higher-level educational objectives:

1. Updatelextend the text itself. The authors produce revised versions of parts of the textbook which are then published on the companion website; more recent work and ideas are synthesised and evaluated into an extended online text (e.g. DrugsBrain, ResStrateg). In terms of the reader's learning objectives, this extended work functions in the same way as the textbook, with the "success" of the companion website depending on the ability of the author to communicate their understanding of the topic in the context of the newer material.

2. Integrate the textbook material with other (newer) resources by linking to them. The authors provide external links to other relevant online resources (e.g. EricMeyCss). Presenting these links in conjunction with a particular topic or part of the book (WebPublish, KimBiology) or annotating the links with a short description of the target resource (BrainWorks) may better enable readers to analyse the linked material in conjunction with the textbook, but the authors themselves do not synthesise the new material into a coherent whole and so therefore this technique may be less effective than (1).

3. Use hypertextual devices to expose the underlying organisational structure of the material. The authors use associative links to make explicit the connections between related topics that could not otherwise be easily expressed in the traditional (non-electronic) textbook medium (KimBiology). This may be more effective than (2) if newer material is synthesised into the hypertext structure, but requires the authors to construct a non-linear information structure.

4. Create exercises which explicitly help readers assess their learning achievements or help instructors assess their students. The authors produce a series of exercises, quizzes, or projects designed to assist readers in self-assessment. Some textbooks may already contain such exercises; observed techniques which go beyond the non-electronic textbook medium include an online answer checker (LightMattr) and automated facilities for student readers to email their answers to their instructor (e.g. Geosystems). Other student resources, such as study guides (ResStrateg, WebPublish), may also help readers focus on the analysis, synthesis, and evaluation of key topics (in particular Geosystem's essay and critical thinking exercises). By the same token, instructor resources such as sample syllabi (Geosystems) and manuals (LightMattr, Powertools) may assist instructors in guiding their students through the spectrum of learning objectives.

Admittedly the first and fourth techniques do not rely on the Web publication medium - revised editions of textbooks and companion "teaching packs" have been the norm since long before the Web (indeed, many textbooks already include exercises for readers); it is only with the widespread adoption of the Web that such revisions and resources can be published quickly and (potentially) reach a wider audience (although copyright restrictions or "commercial" motivations may limit the adoption of this distribution method ${ }^{6}$ ).

Even so, each of the four techniques are susceptible to problems with extensibility related to authoring effort. If the author adopts technique 1 or 2 , the text/links must be revised whenever relevant new material is published in order to keep up to date. Similarly, creating a non-linear information structure (technique 3 ) which incorporates this new material may also be problematic [17]. DrugsBrain contains direct evidence of this problem in it's explanatory text: "the links to the glossary and bibliography were still more complex because each of the several hundred entries had to be identified as a target so the text could be linked to it".

Exercises and assessments (technique 4) also need to take new material into consideration, and may need to be individually created for each type of reader (recall the diverse target readership for $\mathrm{Hy}$ permedia and the Web outlined in Section 2) and knowledge level. Although frameworks such as that provided by Prentice-Hall (e.g. Geosystems) may reduce the effort of actual HTML programming, the fact remains that each of these essentially "static" techniques must be hand-crafted and continually updated by the authors.

\footnotetext{
${ }^{6}$ But note L. Hamilton and C. Timmons' explanatory text to DrugsBrain: "As an example of how a reverse spin can be put on almost anything, we were approached by a textbook editor last week, via e-mail, to inquire if we wanted to publish this [extended, online] book in hard-copy".
} 


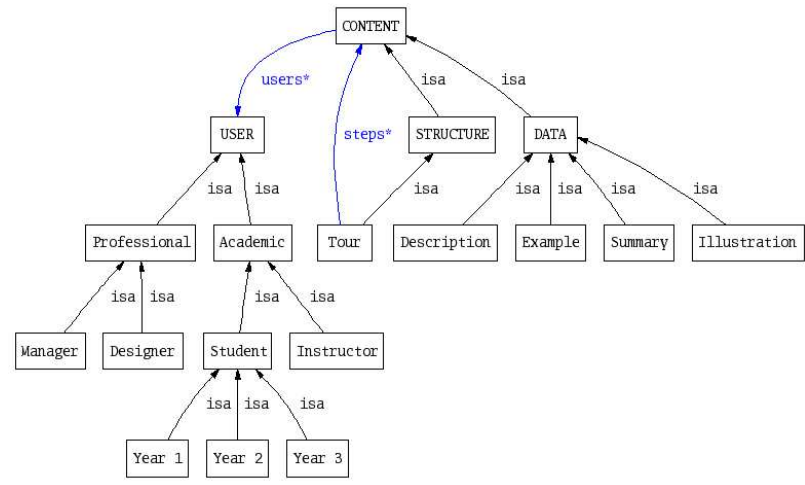

Figure 2: Content unit and readership profiles in the "Hypermedia Engineering" ontology.

\section{COMPANION WEBSITES AND THE SE- MANTIC WEB}

One of the visions of the Semantic Web [2] is the emergence of a "services architecture" [16] advertising the services of "trillions of small specialised reasoning services" [8] operating across a knowledge-enriched Web. Why do these visions make us keen to investigate the Semantic Web as a technology for building companion websites? We reason that in both the construction of a hypertext which exposes the underlying organisational structure of the textbook (and related) material, and the formulation of assessment exercises for students, the authors hold implicit knowledge about the nodes they are creating. For example, the topic to which a particular node refers and the relationships between that topic and others; the target audience of an assessment exercise, including the required intellectual skills and prerequisite knowledge. We envisage this information modelled by an ontology, acquired from the author, and made available to machine-based Semantic Web services whose reasoning over a number of distributed companion websites provides the reader with an integrated, hypertextual view of the online material which takes into consideration their background and knowledge levels.

\subsection{Related Work: Existing Semantic Web Technology}

A number of tools for building the Semantic Web have recently been put forward, and can be related to Bloom's taxonomy.

COHSE [1] uses a ontology of the linguistic terms in the domain of interest (e.g. a thesaurus modelling the relationships between different terms) to add links to Web pages from that domain. Using a semantic model of the terms used in a document, the system is able to make decisions about which links to present to the user, such as suggesting links to resources describing a broader concept in the absence of available resources describing the specific term appearing in the document. schraefel [22] argues that the weakness of COHSE (and similar systems such as MagPie [7] and CREAM [12]) is that the system operates at the lowest levels of Bloom's taxonomy: identifying concepts in a document and giving the reader access to them merely helps the reader recall facts from the knowledge base.

OntoPortal [19] introduced the notion of "ontological hypertext", in which the underlying domain ontology was exposed to the user as an orientation device in order to provide a principled and structured approach to navigating the interconnected knowledge held by the portal. Such an approach to knowledge presentation may bet-

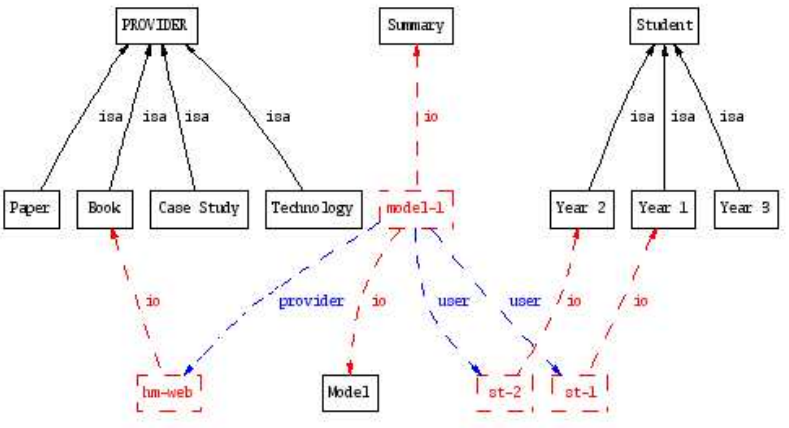

Figure 3: Ontology instances, showing "provider" concept (dotted lines show instances).

ter assist the development of higher level intellectual skills, such as comprehension (through the presentation of related knowledge in context), and analysis (through the revealing of the underlying organisational structure). ESKIMO [14] adopted a similar portalbased approach, but in addition used bibliometric-based inferencing services to derive additional facts from the knowledge base (e.g. allowing the user to discover who are the experts in Hypertext?). ScholOnto [23] provided a framework for a community to construct a network of claims describing their contributions, and the contributions of others, using an ontology of rhetorical relations. Reasoning services which derive trends and patterns from these claims may better reflect the "real-world" opinion, being grounded in human-authored beliefs.

\section{IMPLEMENTATION AND FUTURE WORK}

We have built a companion website for the Hypermedia and the Web textbook which leverages, using Semantic Web technologies, some of the techniques we identified in Section 3.5 for building "successful" companion websites. We also discuss a practical model for future developments of our companion website in the context of a thriving e-commerce, e-publishing, Semantic Web services architecture.

\subsection{Modelling the Textbook}

The first step was to model the concepts in the textbook. Following John Kimball's (KimBiology) lead, we broke the linear textbook down into a number of concise topics - however, rather than mapping these topics directly to HTML web pages, we used them to form the concepts in a "Hypermedia Engineering" ontology modelled using Protégé ${ }^{7}$ [20]. By carefully reading the text, we distilled the key relationships between the identified concepts, and captured them in our ontology (Figure 1).

We were also keen to capture the different "content types" of knowledge unit available in the textbook (e.g. a concept has at least one description, summary, example, or illustration associated with it) and readership profiles (e.g. a concept description/summary etc. may be written with a practitioner, student, or instructor in mind) in our ontology (Figure 2). We also introduced the notion of Providers, with each knowledge unit being "provided by" a Provider instance (Figure 3). To bootstrap the system, we have included a number of knowledge units from three different providers: the $\mathrm{Hy}$ permedia and the Web textbook itself, the HyperBank case study

\footnotetext{
${ }^{7}$ Although Protégé served us well during the first stages of design and implementation, we were later frustrated by the lack of support for multiple instancing (Figure 3).
} 


\begin{tabular}{|c|c|c|c|}
\hline \multicolumn{2}{|c|}{ Service } & Parameter & Result \\
\hline \multicolumn{4}{|l|}{ Concept } \\
\hline & Info & Concept instance URI & Returns data describing given concept, e.g. title, description, provider URI. \\
\hline & $\mathrm{Nav}$ & Concept instance URI & $\begin{array}{l}\text { Returns URIs of related concept instances as modelled by the ontology to facili- } \\
\text { tate ontological hypertext. }\end{array}$ \\
\hline \multicolumn{4}{|r|}{$\begin{array}{llll} & \end{array}$} \\
\hline & Info & Tour instance URI & $\begin{array}{l}\text { Returns data describing given tour, e.g. theme, steps (ordered list of CONTENT } \\
\text { instance URIs - see Figure 2), provider URI. }\end{array}$ \\
\hline & Nav & Concept instance URI & $\begin{array}{l}\text { Finds the tour which the given concept appears in and derives contextual data to } \\
\text { assist user navigation of that tour (URI of next/previous steps on tour, and URI } \\
\text { of parent tour if current tour is a subtour). }\end{array}$ \\
\hline \multicolumn{4}{|r|}{ 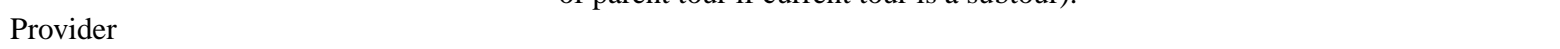 } \\
\hline & Info & Provider instance URI & Returns data describing given provider, e.g. name, description, Web URL. \\
\hline & Nav & Concept instance URI & $\begin{array}{l}\text { Returns URIs of concept instances associated with different providers describ- } \\
\text { ing the given concept, to facilitate integrated exploration of several knowledge } \\
\text { sources. }\end{array}$ \\
\hline
\end{tabular}

Table 3: Services operating over the 3store database.

from the textbook, and material from the more recent WebML Web engineering initiative ${ }^{8}$. In order to provide a basic means of navigating through the site, a guided path was created through each provider's material, independent of the ontological relationships between concepts [9] (Tour concept in Figure 2).

\subsection{System Architecture}

Figure 4 illustrates the current architecture of the Hypermedia and the Web companion website. Our ontology (exported from Protégé to RDF Schema) and instances (exported to RDF) are stored and accessed through the 3store RDF storage and query engine [13], a robust and scalable knowledge base for the Semantic Web ${ }^{9}$. User interaction currently takes place via the services of a HyperBook "agent" the 3 store database (Table 3 ) in order to construct a Web document based on the user request (Figure 5). As well as rendering the content of the current topic, the page also orients the reader within the guided tour, and provides links to related topics, as captured by the ontology. The reader also has the option of switching the "viewpoint' of the topic to that of a different provider (the provider of the currently displayed topic is always visible at the top of the page).

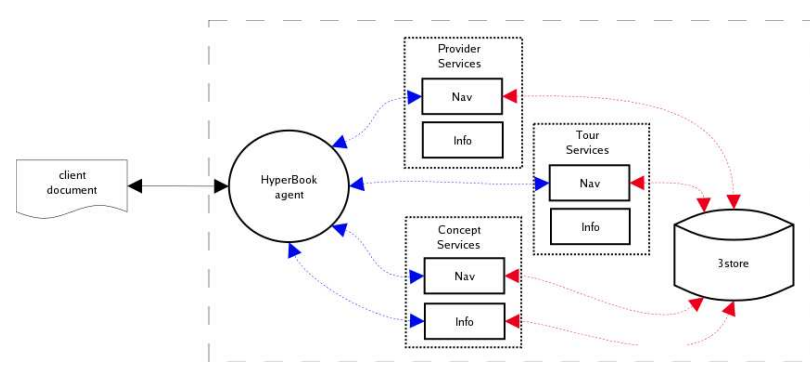

Figure 4: Architecture of Hypermedia and the Web companion website.

\footnotetext{
${ }^{8}$ http://www.webml.org

${ }^{9}$ http://www.aktors.org/technologies/3store/

${ }^{10}$ In this context, we use the term agent to describe simply a computer program which constructs information presentations at the request of the user; we hope to move towards agent-based Semantic Web services [10].
}

\subsection{An E-commerce, E-publishing Semantic Web Scenario}

Figure 6 illustrates how our vision of the future of companion websites in the Semantic Web leverages the advantages of a services architecture: "loosely-coupled distributed systems which adapt to ad-hoc changes by the use of service descriptions that enable opportunistic service discovery" [10].

\subsubsection{Publishing Model}

Providers (e.g. textbook authors, textbook publishers) publish semantically enriched companion website content in distributed knowledge bases (C). As in the case of Geosystems, the textbook publisher may provide a publishing platform to assist authors of their textbooks.

\subsubsection{Advertising agent services to the user}

A number of "agent-based services" [10] (A) register with a discovery service (B) the types of service they offer to particular user stereotypes [21]. When a user visits a particular companion website (in the traditional way, by entering a URL or following a link), and is assigned an initial stereotype, the available services for that stereotype and profile are advertised. The user's profile information may be retrieved from a user profile knowledge base if the user has previously registered.

In this example, the user is a Year 2 Student, and therefore is offered the services of two agents:

- The Revision Notes agent dynamically constructs revision exercises based on the user's selected topic, and their background knowledge)

- The HyperBook agent is an extension of the agent described in the previous section, which takes into consideration the background knowledge of the user when generating pages for the companion website and uses a variety of "adaptive hypertext" techniques [4] to present the most appropriate information.

\subsubsection{User contracts agent to compile required com- panion website "view"}

Acting on behalf of the user, the chosen agent negotiates with a number of Semantic Web services [16] (D) operating over the provider knowledge bases- advertised through a discovery service 


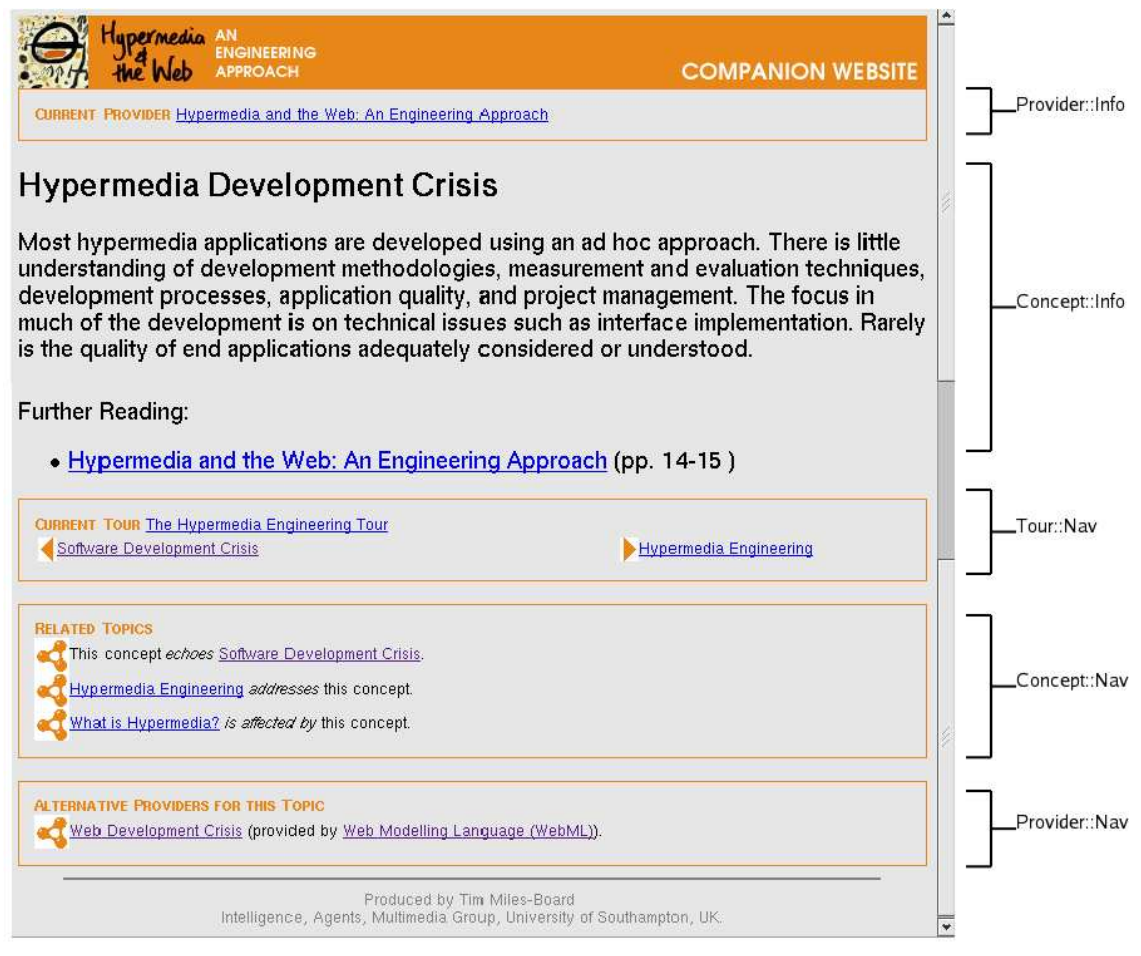

Figure 5: A page from the Hypermedia and the Web, generated by the HyperBook agent using data provided by several Semantic Web services (labelled).

(E) — in order to retrieve the most valuable information for the user's current requirements.

In the example in Figure 6, the user has enlisted the services of the Revision Notes agent to construct a series of questions about Design in Hypermedia Engineering, to help revise for an upcoming test on a course based on the Hypermedia and the Web textbook. The Revision Notes agent requests knowledge units created for Year 2 Students to self-assess their knowledge of Design and related concepts (according to the ontological relationships) from the Questions service (a service specialising in providing exercises, quizzes and other assessments).

The agent may negotiate with multiple, rival, Questions services for this information, e.g. trading coverage for questions on key topics only (the student has left revision to the last minute!), or negotiating provider fees - buying in bulk from Provider A may get more questions for less, but is Provider $B$ (who does not offer bulk buy options) more relevant to the student (appearing as it does in the list of core texts for the course)?

\subsubsection{Further Examples}

The Revision Notes agent working on behalf of an Instructor who wishes to compile a test on Design operates in a similar way, but negotiates for questions intended to help instructors assess student knowledge within the "trust" layer of the Semantic Web [2] to ensure that the "instructor" isn't actually an enterprising student trying to find the answers to the upcoming test!

As another example, the Lecture Slides agent, acting on behalf of an Instructor wishing to compile a series of slides for a half-hour lecture on Hypermedia in the context of Hypermedia Engineering to be given to Year 1 Students, favours any content that can be obtained on related topics from Illustration services, but falls back on the Summary services, or even (as a last resort) Description ser- vices (possibly further enlisting a Summarisation service to reduce the information to a more manageable size given the constraints of the target presentation format), in order to provide coverage of the key topics.

\section{CONCLUSION}

This paper has reported the latest efforts of a project to design and build a companion website which helps keep the textbook $H y$ permedia and the Web: An Engineering Approach (published in 1999) up to date with recent technological advances in the Web Engineering field. This paper has two main contributions. First we have reviewed 25 companion websites from a variety of different domains and enumerated the authoring and presentation techniques which both extend the coverage of the text and help to facilitate readers' higher-level learning objectives (as delineated by Bloom's taxonomy). The review identified four such techniques:

\section{Update/extend the text itself.}

2. Integrate the textbook material with other (newer) resources by linking to them.

3. Use hypertextual devices to expose the underlying organisational structure of the material.

4. Create exercises which explicitly help readers assess their learning achievements or help instructors assess their students.

We argued that these techniques offer little in the way of extensibility; whenever new material is published, the author must update the essentially 'static' content. The second contribution is therefore the proposal that the Semantic Web technologies may help overcome, or at least reduce, the effects of these weaknesses. 


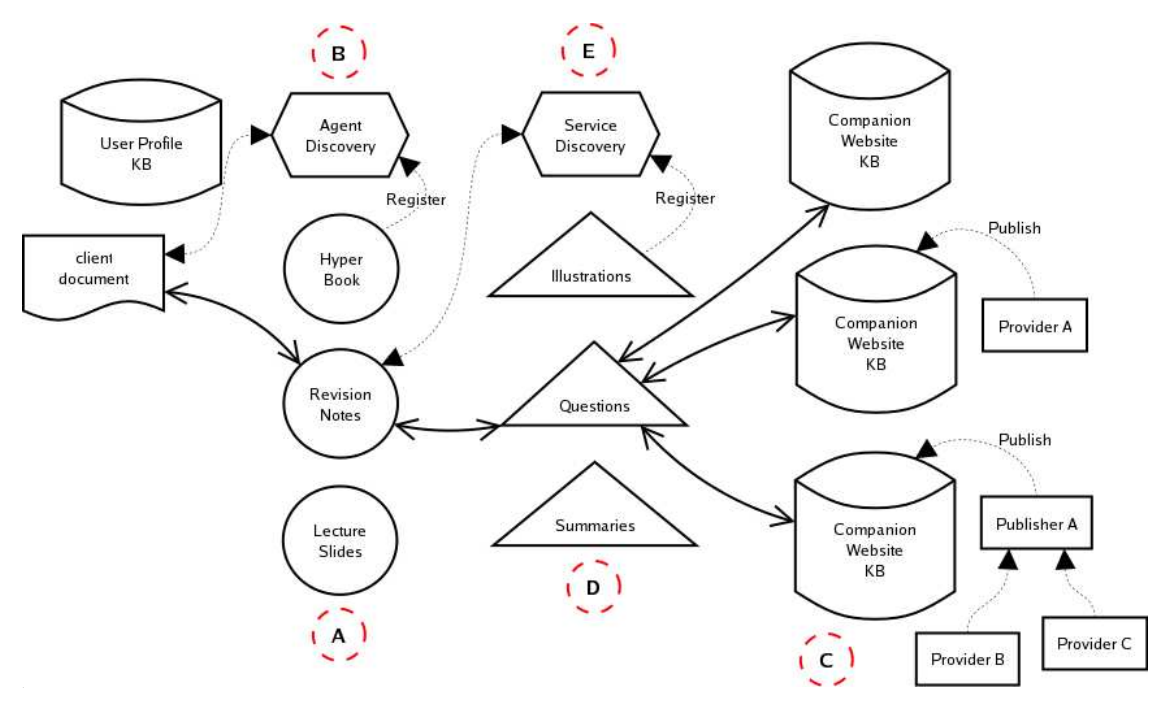

Figure 6: Our vision of the future of companion websites in the Semantic Web.

Our current companion website implementation demonstrates how material from a number of different providers can be dynamically synthesised with material from the Hypermedia and the Web textbook by a (human-programmed) HyperBook agent, thereby "extending' the textbook to cover newer work. In this implementation, the textbook authors need only create knowledge units describing the new work (as opposed to synthesising the new material manually). The HyperBook agent also renders the underlying structure of the material as ontological hypertext, facilitating the user's anal$y$ sis of the subject area.

In the future we hope that agent-based Semantic Web services will dynamically construct other resources as part of the services offered by our companion website, for example negotiating with commerce-based agents to build a cost-effective list of revision notes for a student or a comprehensive syllabus for a course instructor.

\section{REFERENCES}

[1] S. Bechhofer, L. Carr, C. Goble, W. Hall, and D. De Roure. Conceptual linking: Ontology-based Open Hypermedia. In Proceedings of the Tenth International World Wide Web Conference, Hong Kong, May 2001.

[2] T. Berners-Lee, J. Hendler, and O. Lassila. The Semantic Web. Scientific American, May 2001.

[3] B. S. Bloom, editor. Taxonomy of Educational Objectives: Handbook 1. Cognitive Domain. Longman, New York, 1956.

[4] P. Brusilovsky. Adaptive hypermedia. User Modeling and User-Adapted Interaction, 11:87-110, 2001.

[5] S. Ceri, P. Fraternali, and A. Bongio. Web Modeling Language (WebML): a modeling language for designing Web sites. Computer Networks (Amsterdam, Netherlands: 1999), 33(1-6):137-157, June 2000.

[6] S. J. DeRose. Expanding the notion of links. In Proceedings of the Hypertext'89 Conference on Hypertext, Pittsburgh, Pennsylvania, USA, pages 249-257, 1989.

[7] M. Dzbor, J. Domingue, and E. Motta. Magpie - towards a Semantic Web browser. In Proceedings of the 2nd International Semantic Web Conference, Florida, Oct. 2003.

[8] D. Fensel. Ontoknowledge: Intelligent information brokering in intranets. http: / /www. ontoknowledge.org/ countd/countdown.cgi?1review-otk.pdf, 2000.

[9] R. Furuta, F. M. Shipman, C. C. Marshall, D. Brenner, and H. wei Hsieh. Hypertext paths and the World-Wide Web: Experiences with Walden's paths. In Proceedings of the ACM Hypertext 1997 Conference, Southampton, UK, pages 167-176, 1997.

[10] N. Gibbins, S. Harris, and N. Shadbolt. Agent-based Semantic Web services. In Proceedings of the Twelfth International World Wide Web Conference, Budapest, Hungary, May 2003.

[11] S. W. Haas and E. S. Grams. A link taxonomy for Web pages. In Proceedings of the 61st Annual Meeting of the American Society for Information Science, pages 485-495, 1998.

[12] S. Handschuh and S. Staab. Authoring and annotation of Web pages in CREAM. In Proceedings of the Eleventh International World Wide Web Conference, Honolulu, Hawaii, USA, 2002.

[13] S. Harris and N. Gibbins. 3store: Efficient bulk RDF storage. In Proceedings of the 1st International Workshop on Practical and Scalable Semantic Systems (PSSS'03), Sanibel Island, Florida, pages 1-15, 2003.

[14] S. Kampa. Who are the Experts? E-Scholars in the Semantic Web. PhD thesis, Department of Electronics and Computer Science, University Of Southampton, 2002.

[15] D. Lowe and W. Hall. Hypermedia and the Web: An Engineering Approach. Wiley, 1999.

[16] S. McIlraith, T. C. Son, and H. Zeng. Mobilizing the Semantic Web with DAML-enabled Web services. In Proceedings of the Second International Workshop on the Semantic Web, pages 82-93, 2001.

[17] E. Mendes and W. Hall. Towards the prediction of development effort for Web applications. In Proceedings of the ACM Hypertext 2000 Conference, San Antonio, Texas, USA, pages 242-243, May 2000.

[18] T. Miles-Board, L. Carr, and W. Hall. Looking for linking: Associative links on the Web. In Proceedings of the ACM Hypertext 2002 Conference, Maryland, USA, 2002.

[19] T. Miles-Board, S. Kampa, L. Carr, and W. Hall. Hypertext in the Semantic Web. In Proceedings of the ACM Hypertext 
2001 Conference, Arhus, Denmark, 2001.

[20] N. F. Noy, M. Sintek, S. Decker, M. Crubezy, R. W. Fergerson, and M. A. Musen. Creating Semantic Web content with Protégé-2000. IEEE Intelligent Systems, 16(2):60-71, 2001.

[21] E. Rich. Stereotypes and user modeling. In A. Kobsa and W. Wahlster, editors, User Models in Dialog Systems. Springer, 1989.

[22] m. c. schraefel, L. Carr, D. De Roure, and W. Hall. A hypertext carol: You've got hypertext or the future of hypertext is in the email. Journal of Digital Information, Special issue on Future Visions of Common-Use Hypertext, Nov. 2003.

[23] V. Uren, S. Buckingham-Shum, G. Li, J. Domingue, and E. Motta. Scholarly publishing \& argument in hyperspace. In Proceedings of the Twelfth International World Wide Web Conference, Budapest, Hungary, 2003.

[24] Y. Yesilada, R. Stevens, and C. Goble. A foundation for tool based mobility support for visually impaired Web users. In Proceedings of the Twelfth International World Wide Web Conference, Budapest, Hungary, pages 422-430, 2003.

[25] L. Zeng, B. Benatellah, M. Dumas, J. Kalagnanam, and Q. Z. Sheng. Quality driven Web services composition. In Proceedings of the Twelfth International World Wide Web Conference, Budapest, Hungary, pages 411-421, 2003.

\section{APPENDIX}

\section{A. REVIEWED COMPANION WEBSITES}

[AmericGeog] An Outline of American Geography: Regional Landscapes of the United States

http://odur.let.rug.nl/〜usa/GEO/index.htm

[BasConMath] Basic Concepts of Mathematics

http://www.trillia.com/zakon1.html

[BrainThink] How Brains Think

http: //faculty.washington.edu/wcalvin/bk8/

index.htm

[BrainWorks] How The Brain Works Homepage

http://dubinweb.com/brain/index.html

[CompAnalys] Complex Analysis: for Mathematics and Engineering

http: //www.ecs.fullerton.edu/ mathews/c2000/

[DrugsBrain] Drugs, Brains and Behavior

http://www.rci.rutgers.edu/ lwh/drugs /
[ElemsStyle] Elements of Style

http: / /www. bartleby.com/141/

[EricMeyCss] Eric Meyer on CSS

http: / /www .ericmeyeroncss.com/

[FamPractic] Family Practice Handbook

http://www.vh.org/adult/provider/

familymedicine/FPHandbook/FPContents.html

[Geosystems] Geosystems Fourth Edition

http://cwx.prenhall.com/bookbind/pubbooks/

christopherson4/

[InfoTheory] Information Theory, Inference, and Learning Algorithms

http://www.inference.phy.cam.ac.uk/mackay/

itila/

[InsAnatomy] Instant Anatomy

http: / /www . instantanatomy . net/

[JavaScrMag] JavaScript + CSS + DOM Magic

http: //www.createwebmagic.com/

[JavaScrWww] Javascript for the World Wide Web

http: //www. javascriptworld.com/

[KimBiology] Kimball's Biology Pages

http://biology-pages.info/

[LightMattr] The Light and Matter series of introductory physics textbooks

http: //www. lightandmatter.com/areal.html

[MedMicrobi] Medical Microbiology

http://gsbs. utmb.edu/microbook/

[MolBiology] Molecular Biology 2nd Edition

http: //www. mhhe.com/biosci/cellmicro/weaver2/

[PowerTools] Power Tools for Technical Communication

http://www.io.com/ hcexres/power_tools/

[ResStrateg] Research Strategies: Finding Your Way Through the Information Fog

http: / / www. acts.twu.ca/lbr/textbook.htm

[StatsSqOne] Statistics at Square One

http://bmj.bmjjournals.com/collections/

statsbk/index.shtml

[TheWikiWay] The Wiki Way

http: / /www.wiki.org/

[Think Java] Thinking in Java

http: //www.mindview. net/Books/TIJ/

[WebPublish] Philip and Alex's Guide to Web Publishing

http://philip.greenspun.com/panda/

[WordFreque] Word Frequencies in Written and Spoken English

http: //www. comp. lancs.ac.uk/ucrel/bncfreq/ 